\title{
A interculturalidade em Educação Patrimonial: desafios e contributos para o ensino de História
}

\section{Interculturality in Heritage Education: challenges and contributions to History teaching}

\author{
Helena Pinto ${ }^{1}$
}

\begin{abstract}
RESUMO
No ensino de História, aspectos curriculares interdisciplinares relacionados com o uso do património cultural ou a problematização em torno do desenvolvimento de atitudes de tolerância, de respeito pela diferença e cooperação entre povos, necessitam de uma reflexão fundamentada e sistemática sobre concepções de alunos e professores em áreas centrais para a Educação Histórica, como a da interculturalidade. Com o objetivo de aprofundar, numa abordagem essencialmente qualitativa, a compreensão dos sentidos atribuídos por alunos e professores a fontes patrimoniais, em articulação com conceitos ligados à consciência histórica, nomeadamente os de identidade e de património, analisaram-se as concepções de alunos de $7 .^{\circ}$ ano e de $10 .^{\circ}$ ano de várias escolas do norte de Portugal, acerca da forma como interpretam fontes patrimoniais e, ainda, como os seus professores entendem o uso de fontes patrimoniais no ensino e aprendizagem de História, dada a sua relação com a interpretação como processo de construção de significado acerca do passado. Neste estudo registaram-se diferentes perfis de identidade consoante o padrão de pensamento, desde uma identidade local/nacional fundada nas origens, i.e. exclusiva, até uma identidade mais inclusiva e europeia/global. Os resultados do estudo permitem abrir possibilidades de novas formas de abordagem educativa relacionadas com a utilização do património como evidência histórica, contribuindo para o desenvolvimento da consciência histórica e patrimonial.

Palavras-chave: Educação Histórica e Patrimonial; consciência histórica; identidade; interculturalidade.
\end{abstract}

DOI: $10.1590 / 0104-4060.48650$

1 Investigadora Integrada do Centro de Investigação Transdisciplinar "Cultura, Espaço e Memória". Universidade do Porto. Porto, Portugal. Faculdade de Letras. Via Panorâmica, $s / n^{\circ}$. CEP: 4150-564.E-mail: mhelenapinto@gmail.com 


\begin{abstract}
In History teaching, interdisciplinary curricular aspects related to the use of cultural heritage or the questioning of the progress of improvement acts on tolerance, respect for differences and cooperation among peoples require a reasoned and systematic reflection on students and teachers' conceptions in central areas for History Education, such as interculturality. In this research it was aimed at deepening, in an essentially qualitative approach, the understanding of how students and teachers make sense of heritage sources, and also of concepts related to historical consciousness, such as identity and heritage. We have analysed the conceptions of $7^{\text {th }}$ and $10^{\text {th }}$ graders of several schools in northern Portugal, dealing with heritage evidence, and how their teachers understand the use of heritage sources in teaching and learning History, given its relationship with interpretation as a process of making sense of the past. Different identity profiles emerged from data analysis depending on the pattern of thinking, from a local/national identity grounded on origins, i.e. exclusive, up to a more inclusive and European/global identity. The results of this study revealed possibilities of new educational approaches regarding the use of heritage as historical evidence, and contributing to the development of historical and heritage consciousness.
\end{abstract}

Keywords: History and Heritage Education; historical consciousness; identity; interculturality.

\title{
O Património Cultural como construção social
}

O património pode revelar as dimensões histórica e cultural de identidades sociais e espaciais. Porém, a apreensão dos seus significados não implica o regresso a um estado de "pureza". A mudança faz parte da história dos homens, dos países, dos lugares, dos edifícios e dos artefactos. Mas as relações entre preservação e apresentação são complexas. Frequentemente observam-se diferenças de tratamento na apresentação de sítios e monumentos que perderam o seu uso original e de edifícios ou lugares com uso contínuo. O contraste entre estruturas que tiveram uso simultâneo, como as ruínas de um castelo e um centro histórico, por exemplo, poderia ser adequadamente explorado e elucidar sobre alterações verificadas ao longo do tempo.

Não podemos evitar refazer o passado, pois só alterando o que se preserva se poderá manter vivo e compreensível o património. (LOWENTHAL, 1999). Praticamente todos os lugares, sejam urbanos ou rurais, industriais ou agrícolas, contêm marcas da atividade humana no passado. Em alguns locais 
há vestígios abundantes nos edifícios e estruturas, outros exigem técnicas como a prospeção e a escavação arqueológica, pois os vestígios estão "escondidos". Por sua vez, em outros locais, várias estruturas ainda estão em uso, embora com funções diferentes das originais. E não podemos esquecer a toponímia, crucial para a compreensão dos espaços urbanos antigos, sobretudo quando os vestígios materiais já não são visíveis. Nesse sentido, é de destacar a toponímia medieval que subsistiu em muitas denominações do espaço urbano, permanecendo, ainda, no uso comum, revelando uma continuidade na ligação ao espaço vivenciado. A toponímia constitui um elemento patrimonial cuja preservação é crucial para evitar a perda de referências mais remotas, pois o nome contribui para a identidade do lugar.

Hoje em dia, sempre que nos deparamos com um nome de rua ou praça que invoque antigos ofícios, tendemos a concluir da sua origem medieval, pois é ideia corrente que foi durante a Idade Média que se vulgarizou essa preferência toponímica. Percorrer essa toponímia, permite não só reencontrar atividades quotidianas, mas também uma aproximação ao dinamismo económico, social e cultural das comunidades. Se esses topónimos traduziam a maneira como o homem medieval se apropriava do espaço urbano, o seu reconhecimento permite recuperar estruturas espaciais, de trabalho, de consumo e crenças.

Com ritmos diversos, mas constantemente, as características culturais de todas as sociedades mudam, e as mudanças conduzem ao desaparecimento de certos elementos até aí familiares: pessoas, comportamentos, diversos saber-fazer, paisagens construídas ou naturais. É nesses momentos que se poderá produzir a tomada de consciência patrimonial.

O património é o resultado de uma seleção que, ao longo do tempo e segundo critérios muito variados, foi colocando determinados elementos na categoria de objetos patrimoniais. As sociedades contemporâneas alargaram de tal forma o conceito de património - material e imaterial, cultural e natural, histórico, arqueológico, artístico, genético... -, que esse parece referir-se, muitas vezes, a formas de expressão de identidades e de memórias coletivas centradas na continuidade. Os mitos de autenticidade, a visão cristalizada do passado, as representações estereotipadas das diferenças culturais, estão muitas vezes presentes nos debates sobre o património e exprimem ideias nostálgicas ou identidades exclusivistas das sociedades. É, por isso, essencial a reflexão acerca das formas como o património se relaciona com a memória e a História, nomeadamente nas sociedades ocidentais, pois disso depende, em grande parte, uma perspetiva mais fechada, exclusivista e monumentalista ou mais aberta, inclusiva e historicizada dessa relação. 


\section{Interculturalidade e consciência histórica}

Rüsen (2014) considera que o pensamento científico é, ele próprio, uma atividade cultural, tornando-se assim compreensível a sua utilidade para a vida. Relaciona-se com a práxis de orientação cultural, da qual se distinguem as ciências com suas formas específicas de conhecimento, ou teoria. Por isso considera que, na vida cultural,

[...] a formação humana de sentido se apresenta como um todo, marcado por multiplicidade, divergência, permanente mudança e, ao mesmo tempo, unido pela necessidade vital, comum a todos os seres humanos, de produzir a sua própria natureza em forma de cultura. (RÜSEN, 2014, p. 13).

Ao tornar evidente a ligação entre a História e a interculturalidade, tendo como pressupostos de base a diversidade e a universalidade do ser humano, Rüsen (2002) defende que a capacidade de agir (enraizada na subjetividade) está fundamentada nas relações que o ser humano estabelece entre si e com a natureza e que essas relações são algo permanente no tempo.

O ser humano tem que interpretar seu mundo e a si mesmo para poder viver nele e consigo mesmo. Por isso, Rüsen (2014, p. 26) considera que "toda a identidade cultural se refere à subjetividade daqueles que querem saber quem são e como se diferenciam dos outros", dado que essa subjetividade é efeito da transformação da natureza em cultura e as relações inerentes à multiplicidade cultural fundamentam-se nessa transição genérica.

Outra função cultural importante é assumida pela memória histórica e pela consciência histórica, ao contribuírem para formar a identidade, atendendo a uma perspectiva temporal. (RÜSEN, 2002). A consciência histórica tem, por isso, a função prática de fornecer uma orientação temporal que pode guiar a ação intencionalmente pela mediação da memória histórica. Porém, adverte Lowenthal (1999), a história difere da memória não só na forma como o conhecimento do passado se adquire e é validado, mas também no modo como se transmite, preserva e transforma: "Aceitamos a memória como uma premissa do conhecimento; inferimos a história pela evidência que inclui as memórias de outras pessoas". (LOWENTHAL, 1999, p. 213). Contrariamente à memória, a história não é dada, mas contingente, pois baseia-se em fontes empíricas que podemos decidir rejeitar por outras versões do passado. 
O conceito de consciência histórica tem sido frequentemente confundido com identidade, ganhando, umas vezes, contornos de identidade nacional, outras, de identidade local, ou até de simples sentido de pertença a um grupo específico (social, económico, político, religioso...). É frequente, entre a opinião pública, a perceção de que a História, e o património em particular, contribuem para a identidade coletiva através do desenvolvimento de uma cultura comum. Verifica-se, de facto, uma partilha de significados acerca do passado, e esses podem revelar uma identidade local, nacional, de carácter fixo, ou integrar identidades múltiplas e abertas, de carácter flexível.

A base para a compreensão da vida no passado - e, portanto, do saber histórico - é a experiência do quotidiano que, com os seus interesses e funções, compele o sujeito a buscar no passado elementos úteis, significativos para as suas decisões no presente, com vista a um melhor futuro. O saber histórico, que deriva dessa necessidade, com as suas formas, métodos e conceitos, vai influenciar, por sua vez, o quotidiano dos seres humanos.

Também Chapman e Facey (2004) sublinham a diversidade dos modos de relacionamento com o passado e chamam a atenção para o facto de algumas dessas formas de relacionamento serem mais "históricas" do que outras.

Em ligação com essa problemática da consciência histórica, a significância histórica é uma das ideias de segunda ordem cuja emergência tem sido evidente no pensamento histórico dos jovens em situações históricas pontuadas pelo diálogo ou o conflito. (CASTRO, 2006). Para Cercadillo (2006) a significância pode emergir no pensamento histórico dos jovens por força de fatores relacionados com os seus interesses (ancorados em identidades de cariz nacional, étnico ou social) - sendo, neste caso, uma significância de tipo subjetivo. Por sua vez, será de tipo objetivo quando emerge do processo de construção da narrativa histórica.

Na sua investigação, Castro (2006) apresentou, com base na análise de dados, cinco níveis de progressão sobre a compreensão histórica dos alunos em torno de noções de significância e de empatia histórica, bem como de diferença, diversidade e relação. Se no nível de "compreensão restrita" as ideias dos alunos centram-se na descrição do acontecimento, numa perspectiva fixa, e a informação emerge como autoridade inquestionável; há uma atitude de indiferença face ao passado e à explicação sobre ele; o conceito de "outro" tende a ser objetivado e a "diferença" ocupa o centro da atenção, através de comparação e numa posição auto e/ou etnocentrada, pelo que as ideias emergem em torno da "multiculturalidade". No nível mais sofisticado de "compreensão descentrada integradora" observa-se uma seleção crítica e consistente da informação, considerando-a no seu contexto de mensagem e de produção; a multissignificância é explícita e a reconstrução do passado é feita de forma contextualizada e com base em argumentos abertos a novas possibilidades, numa postura descentrada; o conceito de 
'relação' é central e em conexão com ideias de "universalidade"; por isso, a noção de "interculturalidade" implica a compreensão de uma universalidade plural.

\section{Interculturalidade e Ensino de História: a pesquisa em educação histórica e patrimonial}

Seguindo uma perspectiva de Educação Histórica que se desenvolve em diálogo com o próprio saber historiográfico e que coloca esse saber como referência para a progressão conceptual dos estudantes, a investigação nesse campo considera fundamental conhecer como os jovens constroem o seu pensamento histórico. Essa investigação tem avançado no campo epistemológico e empírico, com enfoque no diagnóstico de concepções de alunos e professores acerca da História, e também tem contribuído, de forma sistemática, para ligar a teoria à prática, como revelam estudos realizados em diversos países e continentes.

Ao nível da Educação Histórica, merece destaque a problematização sistemática dos "usos" da História e do património, com vista à elaboração de propostas de desenvolvimento do pensamento histórico de jovens e de abordagens metodológicas dos educadores. Simultaneamente, ao nível da Educação Patrimonial, a implementação de atividades de contato direto com fontes patrimoniais permite despertar nos jovens sentidos de responsabilidade em relação ao património histórico, e ainda a reflexão crítica e construtiva face às memórias das comunidades com vista à compreensão temporal.

Referindo-se à interpretação dos objetos de museus, Hooper-Greenhill (1999) sugere que a construção de significados depende do conhecimento anterior e das crenças e valores pré-existentes. Vemos de acordo com o que sabemos, e damos sentido de acordo com o que vemos. Dessa forma construímos os significados, mas não de forma definitiva. A construção de significados depende da forma como relacionamos o passado com o presente. Toda a interpretação é, por isso, historicamente situada. (HOOPER-GREENHILL, 1999, p. 13).

Várias pesquisas no âmbito da educação em museus (ANDREETTI, 1993; DURBIN, MORRIS; WILKINSON, 1996; ESTEPA; CUENCA, 2006; FONTAL, 2003; HEIN, 1998; HOOPER-GREENHILL, 1999; MATOZZI, 2001; RAMOS, 2004) e na linha da Educação Histórica (ASHBY; LEE; SHEMILT, 2005; CHAPMAN, 2006, COOPER, 2004; CAINELLI, 2006; NAKOU, 2003; SEIXAS; CLARK, 2004; SCHMIDT; GARCIA, 2006, 2007) têm afirmado a possibilidade de desenvolvimento do pensamento histórico nos alunos por meio 
da interpretação dos objetos da cultura material, dotados de significado histórico (PINTO, 2013; PINTO; MOLINA, 2015; SANTACANA; LLONCH, 2012).

A implementação de atividades de Educação Histórica e de Educação Patrimonial é fundamental se desenvolvida de forma sistemática e segundo critérios metodológicos. Ao nível da educação formal, no que respeita ao Ensino de História, é essencial:

- proporcionar recursos e atividades desafiadoras das concepções prévias dos alunos;

- selecionar conteúdos relacionados com a história local, introduzindo de forma interessante e adequada ao currículo a abordagem do património, recorrendo a um museu ou a um sítio histórico na área próxima da escola;

- usar fontes patrimoniais de forma a desenvolver a compreensão dos conceitos históricos pelos alunos e a interpretação dos contributos culturais, sociais e económicos de diversos grupos nas suas comunidades.

Os currículos tradicionais concentravam-se excessivamente na apresentação da herança nacional aos alunos e tratavam a História como um corpo de informação recebida para ser aceite e memorizada; as "fontes primárias" eram apenas usadas ocasionalmente para estimular a curiosidade, o interesse, ou para ilustrar casos particulares. Contudo, ainda se verifica, quer nos programas quer na prática de sala de aula, um enfoque em fontes escritas, pelo que a utilização de fontes patrimoniais em contexto não é tão frequente como seria desejável. (PINTO; MOLINA, 2015).

Se o património é uma realidade multifacetada, são também multíplices os "olhares" ou abordagens que a ele se podem dirigir. Segundo Estepa e Cuenca (2006), devemos estabelecer critérios básicos relativos à inserção do património no currículo - dentro das grandes metas estabelecidas para a educação sistematizada, a formação da cidadania em geral e para as didáticas das ciências sociais e experimentais, em particular - " [...] partindo de para quê educamos em património, que formação patrimonial devemos promover e como a desenvolvemos e a avaliamos". (ESTEPA; CUENCA, 2006, p. 53). O conhecimento desse legado estimula a consciência crítica em relação às nossas crenças e identidades, assim como a outras culturas, nomeadamente pela partilha de valores com outras sociedades. Por isso, a seleção dos conteúdos a ensinar deve partir de uma profunda análise crítica, nomeadamente do ponto de vista epistemológico de cada uma das disciplinas. No que diz respeito à metodologia, esses autores consideram a investigação escolar como o enfoque mais adequado para propiciar aprendizagens significativas, onde a exploração e a investigação do meio, partindo de problemas próximos dos interesses dos alunos, analisando diversas fontes e chegando a conclusões sobre os problemas colocados inicialmente, constitui o eixo fundamental da sequência de atividades da aula. 
Perante a impossibilidade, pelo menos no contexto atual, da integração da educação patrimonial como corpo disciplinar autónomo no currículo, e dada a transversalidade que caracteriza a educação patrimonial e que resulta da heterogeneidade inerente ao património - desde o material ao intangível, do cultural ao natural, do imóvel ao móvel... - parece de toda a pertinência a abordagem de fontes patrimoniais na disciplina de História e a investigação dessas atividades de educação patrimonial no âmbito da Educação Histórica. Essas abordagens podem ser estimuladoras da interpretação histórica, da compreensão da evidência que dá sentido ao passado, mas também promotoras de uma consciência histórica e patrimonial.

\section{Interculturalidade em Educação Patrimonial}

\section{Método do estudo}

Mediante um estudo descritivo, de natureza essencialmente qualitativa, procurou-se aprofundar - numa abordagem sistemática - a compreensão dos sentidos atribuídos por alunos e professores a fontes patrimoniais, em articulação com conceitos ligados à consciência histórica, nomeadamente os de identidade e de património ${ }^{2}$.

Pretendeu-se, assim, responder ao problema central de investigação: De que forma alunos e professores de História interpretam a evidência de um sítio histórico?

O estudo, que assumiu uma abordagem metodológica fundada na Grounded Theory (STRAUSS; CORBIN, 1998), apresentou uma proposta relacionada com a educação histórica e patrimonial. Desenvolveu-se em três fases: exploratória, piloto (em quatro etapas) e principal. No estudo principal, participaram 87 alunos ( $40 \mathrm{de} 7^{\circ}$ ano e 47 de $10^{\circ}$ ano a frequentar a disciplina de História A ou História da Cultura e das Artes) de 5 escolas da cidade de Guimarães, no norte de Portugal, e ainda os professores dos 7 grupos de alunos participantes. Os instrumentos consistiram num "guião-questionário" para os alunos - propondo um conjunto de tarefas escritas a realizar em vários pontos de paragem de um percurso (Figuras 1 a 4), em situação de observação direta e de interpretação de

2 A investigação referida foi apoiada por Bolsa de Investigação no âmbito do QRENPOPH - Tipologia 4.1 - Formação Avançada, comparticipada pelo Fundo Social Europeu e por fundos nacionais do MCTES com a referência: SFRH/BD/36616/2007. 
um conjunto de fontes patrimoniais relacionadas com a Idade Média, mas tendo em conta a sua historicidade, e dois breves questionários para os professores (um prévio e outro posterior à atividade). Realizaram-se, ainda, entrevistas de seguimento a 33 alunos no sentido de clarificar algumas respostas escritas.

\section{FIGURAS 1 A 4 - GRUPOS DE ALUNOS DE $7^{\circ}$ E $10^{\circ}$ ANO DE ESCOLAS LOCAIS, REALI- ZANDO A ATIVIDADE EM DIVERSOS PONTOS DE UM PERCURSO NO CENTRO HISTÓRICO DE GUIMARÃES, PORTUGAL}
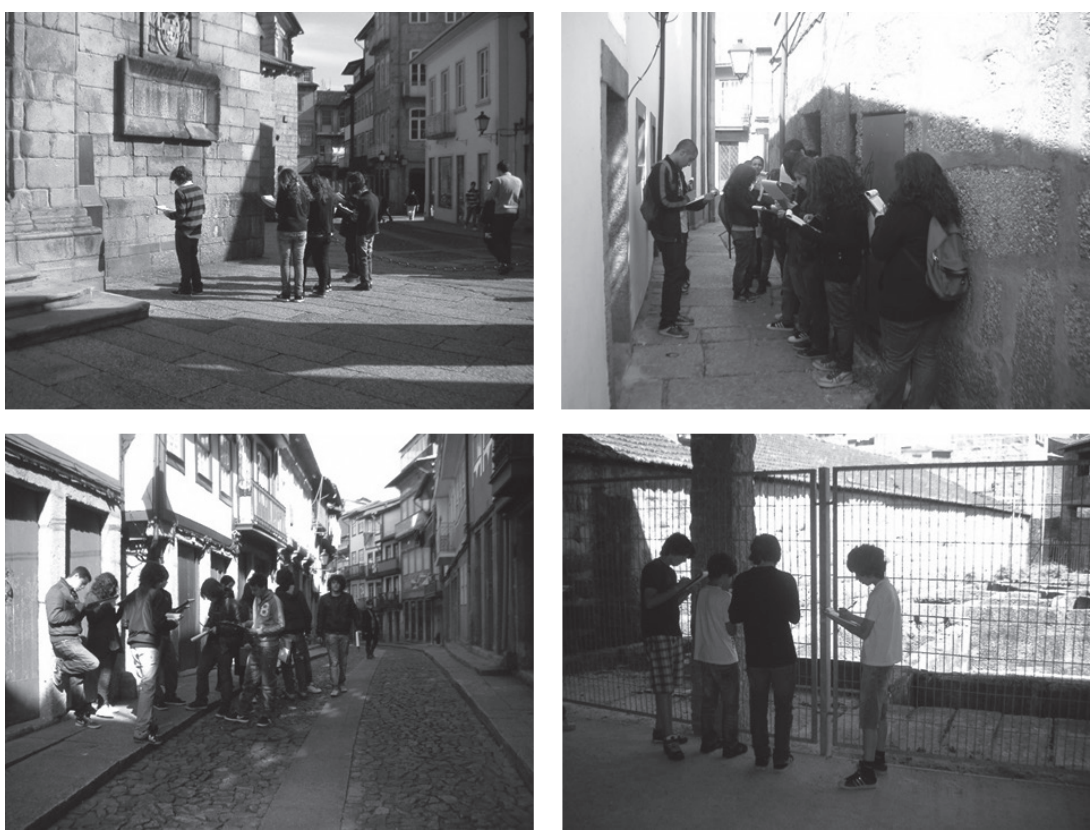

FONTE: A autora (2016).

$\mathrm{Na}$ elaboração dos instrumentos de recolha de dados, nomeadamente o guião-questionário para alunos e os questionários para professores, partiu-se da constatação de que no centro histórico de Guimarães, além do Castelo e do Paço dos Duques de Bragança, há um vasto e diversificado património que ultrapassa a dimensão histórico-arquitetónica, e cuja preservação e enquadramento no tecido urbano e social é importante assegurar. A classificação como Património Cultural da Humanidade, em 2001, associou-lhe uma dimensão universalizante, mas pretender simbolizar uma cultura que se universaliza a partir de fragmentos patrimoniais específicos pode descurar modos de vida e 
expressões culturais locais cuja historicidade, interpretada de forma apropriada, poderia ser um contributo para a compreensão do passado percecionado através dos seus vestígios e do presente vivido.

\section{Análise de dados}

A análise dos dados das respostas dos alunos ao guião-questionário (que responderam à medida que realizaram o percurso) realizou-se de forma indutiva, sendo clarificada, aprofundada e sistematizada ao longo das fases do estudo, no sentido de identificar perfis conceptuais dos participantes e construir modelos de tarefas a aplicar em educação histórica e patrimonial. Os perfis conceptuais referentes às respostas dos alunos foram associados a dois construtos: (1) Uso da Evidência, relativo ao modo como os alunos utilizam a informação de fontes escritas e patrimoniais e inferem a partir do suporte material da evidência; e (2) Consciência histórica, respeitante ao modo como os alunos dão sentido à relação dialógica entre passado e presente, ou seja, os tipos de compreensão que os alunos revelaram acerca do significado do património no passado e no presente, a partir da 'leitura' das fontes patrimoniais, em termos de significância social - compreensão das ações humanas no passado - e de significância pessoal, nomeadamente de ideias acerca da relação passado-presente quanto a características sociais, económicas e culturais.

Os exemplos de respostas de alunos que aqui se apresentam (com nomes fictícios) referem-se ao segundo construto acima exposto. Um grande número de alunos avaliou as atitudes das pessoas do passado à luz de valores do presente ou entendeu o passado, em termos genéricos, como intemporal e provendo conhecimento, revelando apenas consciência de um passado fixo. Outros compreenderam a forma como o património chegou ao presente pelo seu significado como evocação de acontecimentos-chave do passado ou pela sua simbologia em termos de identidade local e/ou nacional. A Isaura ( $7^{\circ}$ ano, 12 anos), por exemplo, revela consciência de um passado simbólico, ao afirmar:

É importante saber o que fomos e porque fomos. E há tantas migalhas de história em Guimarães pelo chão. Tudo isto é importante, não é por acaso que Guimarães vai ser Capital Europeia da Cultura. Durante muitos anos Guimarães foi o princípio dos princípios de Portugal.

Um número significativo de alunos do $10^{\circ}$ ano, mas também do $7^{\circ}$ ano, compreenderam a relação passado-presente de forma linear quanto ao uso e 
função das fontes patrimoniais, embora procedendo à sua contextualização em termos sociais e económicos, revelando uma consciência histórica emergente.

Só algumas respostas revelaram um sentido relacional entre passado, presente e hipóteses de futuro, expressando uma consciência da historicidade das fontes patrimoniais ao reconhecer a sua interpretação de forma contextualizada como fundamental para a compreensão histórica. Assim, surgem em algumas respostas indícios de uma consciência histórica explícita, como se verifica na resposta da Luísa ( $10^{\circ}$ ano, Hist. A, 15 anos):

Penso que na maioria das vezes não nos damos conta da história que a nossa cidade tem. Tantos aspectos que podem ser reconhecidos e aprofundados. Neste percurso vimos construções na cidade, como as casas, orgulho nas construções (lápide), atividades económicas que sempre caracterizaram a cidade e "simples" objetos de proteção. Várias coisas de que nos vamos apercebendo e que tornam esta cidade o que ela é, um centro de cultura para ser explorado por grande parte da população, se não por toda.

No entanto, os níveis conceptuais não são invariantes, mesmo em cada aluno, e nenhum dos níveis é mutuamente exclusivo, pois cada um deles pode emergir num mesmo indivíduo em diferentes contextos, sendo permeável e sujeito a oscilações.

Simultaneamente considerou-se essencial compreender como os professores - mediadores entre as fontes históricas e a sua interpretação pelos alunos - tomam consciência da importância do uso das fontes patrimoniais como evidência, de acordo com critérios metodológicos da História. Quanto às concepções de professores, também emergiu um modelo conceptual em torno de dois construtos: (1) Uso de fontes patrimoniais, relativo ao modo como os professores procuram mediar a relação que os seus alunos estabelecem com os vestígios do passado em atividades de ensino e aprendizagem de História; e (2) Finalidades de ensino e divulgação do património, respeitante às concepções de professores relativas ao modo como perspectivam o contributo da exploração de fontes patrimoniais na aprendizagem de História pelos alunos; os tipos de consciência que revelam em relação a esse processo de desenvolvimento do pensamento histórico dos alunos e às ligações que esses podem estabelecer entre identidade e património em termos de orientação temporal.

Por determinações de espaço, exemplificam-se aqui apenas os padrões conceptuais correspondentes à dimensão "Consciência Patrimonial” que integra 
o segundo construto. Os professores revelaram tipos de consciência diversos relativamente às formas como os seus alunos poderão orientar a sua vida prática, baseando-se na relação entre identidade e património que os alunos estabelecem ao interpretarem fontes patrimoniais.

Um professor salientou o respeito pelo património, pelas "marcas do passado", através de objetos específicos que podem "evocar" o passado e devem ser preservados para uso no presente (ideia difusa), o que parece implicar o comprometimento com uma determinada identidade coletiva que condiciona o indivíduo aos seus ancestrais: "Além do conhecimento histórico, o respeito pelas fontes históricas e pelo país, região, cidade que alberga essas fontes". (Helga, prof. $7^{\circ}$ ano, Q.2, questionário prévio).

Algumas respostas realçaram o facto de as atividades de observação direta de fontes patrimoniais estimularem o sentimento de pertença a uma comunidade e a sensibilização para a preservação do património local, considerando que esse materializa a identidade da comunidade, como depositário de casos "exemplares" relevantes para a resolução dos problemas do presente, considerando, por vezes, que aquele seria ignorado pelos alunos. A Heloísa, por exemplo, revela um sentido de identidade local:

Os alunos viram um espaço, que parecia que conheciam, com um outro olhar, observaram coisas pela primeira vez. Aprenderam a ver/observar com outra atenção, o que lhes provocou maior curiosidade e interesse pela História Local e o seu Património, o qual muitas vezes lhes era indiferente. (Heloísa, prof. $7^{\circ}$ ano, Q.2, questionário posterior).

Um número menos expressivo de respostas pareceu revelar a consciência de que é possível ensinar a partir da observação do local para um quadro interidentitário, revelando sentido de identidades múltiplas em termos de consciência patrimonial:

Construção de uma memória coletiva (histórica) comum de âmbito local (suscetivel de ser alargada a um contexto nacional e europeu); sobre a complexidade da construção da "verdade histórica"; a pertinência de saber "olhar" criticamente para os vestígios materiais; integrar e relacionar conhecimentos adquiridos. (Hugo, prof. $10^{\circ}$ ano, Hist. A, Q.2, questionário posterior). 
Assim, diversas respostas dos professores realçaram o facto de as atividades de exploração de fontes patrimoniais estimularem o sentimento de pertença a uma comunidade e a sensibilização para a preservação do património local, considerando que esse materializa a identidade da comunidade, enquanto um menor número pareceu revelar a consciência de que é possível ensinar a partir da observação do local para um quadro interidentitário.

\section{Desafios e contributos para o Ensino de História - breve reflexão}

Neste estudo registaram-se diferentes identidades consoante o padrão de pensamento, desde uma identidade local/nacional fundada nas origens, exclusiva - com uma componente emocional na relação com o passado, no que respeita à identidade assumida como "nós" -, até uma identidade mais inclusiva e europeia/global. A primeira parece ligada a uma abordagem da "memória coletiva" que ainda prevalece no ensino de História, embora já pouco apropriada a um mundo caracterizado pela existência de identidades diversas e, por vezes, controversas. Além disso, o carácter impressionista com que se tem abordado, muitas vezes, no Ensino de História, aspetos curriculares interdisciplinares em torno do desenvolvimento de atitudes de tolerância, de respeito pela diferença e cooperação entre povos, carece de uma reflexão fundamentada e sistemática sobre concepções de alunos e professores em áreas centrais para a Educação Histórica como a da interculturalidade.

É possível, através da história local, introduzir de forma interessante e adequada ao currículo, a abordagem da educação patrimonial no âmbito da disciplina de História, recorrendo a um museu ou a um sítio histórico próximo da escola. Se, por um lado, o desenho de experiências educativas de contacto direto com o património permite promover sentidos de pertença e de diálogo entre culturas, por outro lado, o uso de fontes patrimoniais em tarefas metodologicamente adequadas pode facilitar a compreensão de conceitos históricos mais abstratos pelos alunos e suscitar o envolvimento dos jovens na construção do seu próprio saber e da sua ação presente e futura. 


\section{REFERÊNCIAS}

ANDREETTI, K. Teaching history from primary evidence. London: David Fulton Publishers, 1993.

ASHBY, R.; LEE, P.; SHEMILT, D. Putting principles into practice: teaching and planning. In: DONOVAN, M. S.; BRANSFORD, J. D. (Ed.). How students learn: History in the classroom. Washington DC: The National Academies Press, 2005. p. 79-178.

CAINELLI, M. Educação Histórica: perspectivas de aprendizagem da história no ensino fundamental. Educar em Revista, número especial, p. 57-72, 2006.

CASTRO, J. A. Interculturalidade e o Pensamento Histórico dos Jovens. Tese (Doutoramento em Educação) - Metodologia do Ensino de História e Ciências Sociais, Universidade do Minho, Braga, 2006.

CERCADILLO, L. 'Maybe they haven't decided yet what is right': English and Spanish perspectives on teaching historical significance. Teaching History, 123, p. 6-9, 2006.

CHAPMAN, A. Asses, archers and assumptions: strategies for improving thinking skills in history in years 9 to 13. Teaching History, 123, p. 6-13, 2006.

CHAPMAN, A.; FACEY, J. Placing History: Territory, story, identity - and historical consciousness. Teaching History, 116, p. 36-40, 2004.

COOPER, H. O pensamento histórico das crianças. In: BARCA, I. (Org.). Para uma Educação Histórica de qualidade. Actas das Quartas Jornadas Internacionais de Educação Histórica. Braga: CIEd, Universidade do Minho, 2004. p. 55-74.

DURBIN, G.; MORRIS, S.; WILKINSON, S. Learning from objects: a teachers' guide. London: English Heritage, 1996.

ESTEPA, J.; CUENCA, J. La mirada de los maestros, profesores y gestores del patrimonio. Investigación sobre concepciones acerca del patrimonio y su didáctica. In: CALAF, R.; FONTAL, O. (Ed.). Miradas al patrimonio. Gijón: Ediciones Trea, 2006. p. 51-71.

FONTAL, O. La educación patrimonial: teoría y práctica en el aula, el museo e internet. Gijón: Ediciones Trea, 2003.

HEIN, G. Learning in the Museum. New York: Routledge, 1998.

HOOPER-GREENHILL, E. The educational role of the museum. London: Routledge, 1999.

LOWENTHAL, D. The past is a foreign country. Cambridge: Cambridge University Press, 1999.

MATTOZZI, I. La didáctica de los bienes culturales: a la búsqueda de una definición. In: ESTEPA, J.; DOMÍNGUEZ, C.; CUENCA J. M. (Ed.). Museo y patrimonio en la didáctica de las ciencias sociales. Huelva: Universidad de Huelva, 2001. p. 57-96. 
NAKOU, I. Exploração do pensamento histórico das crianças em ambiente de museu. In: BARCA, I. (Org.). Educação Histórica e Museus. Actas das Segundas Jornadas Internacionais de Educação Histórica. Braga: CIEd, Universidade do Minho, 2003. p. 59-82.

PINTO, H. Educação histórica e patrimonial: conceções de alunos e professores sobre o passado em espaços do presente. Tese (Doutoramento em Ciências da Educação) - Especialidade de Educação em História e Ciências Sociais, Universidade do Minho, Braga, 2011.

PINTO, H. Interpretação de fontes patrimoniais em Educação Histórica. História \& Ensino, v. 18, n. 1, p. 187-218, 2012. Disponível em: <http://www.uel.br/revistas/uel/ index.php/histensino/article/view/13120>. Acesso em: 25 set. 2012.

PINTO, H. Educação patrimonial e educação histórica: contributos para um diálogo interidentitário na construção de significado sobre o passado. Diálogos, v. 19, n. 1, p. 199-220, 2015. Disponível em: <http://www.uem.br/dialogos/index.php?journal=ojs\& page $=$ article \&op $=$ view $\&$ path $\% 5 B \% 5 \mathrm{D}=1049 \&$ path $\% 5 B \% 5 \mathrm{D}=$ pdf_713>. Acesso em: 30 maio 2015.

PINTO, H.; BARCA, I. Uso de fontes patrimoniais e consciência histórica de alunos e professores portugueses. Revista de Educação Histórica - REDUH, 2, p. 114-131, 2013. Disponível em <http://www.lapeduh.ufpr.br/revista/>. Acesso em: 21 jun. 2013.

PINTO, H.; MOLINA, S. La educación patrimonial en los currículos de ciencias sociales en España y Portugal. Educatio Siglo XXI, v. 33, n. 1, p. 103-128, 2015. Disponível em: $<$ http://revistas.um.es/educatio/article/view/222521/174771>. Acesso em: 25 abr. 2015.

RAMOS, F. R. A danação do objeto: o museu no ensino de História. Chapecó: Argos, 2004.

RÜSEN, J. Western Historical Debate. An Intercultural Debate. Oxford: Berghahn Books, 2002.

RÜSEN, J. Historical Consciousness: Narrative Structure, Moral Function and Ontogenetic Development. In: SEIXAS, P. (Ed.). Theorizing Historical Consciousness. Toronto: University of Toronto Press, 2004, p. 63-85.

RÜSEN, J. Cultura faz sentido: orientações entre o ontem e o amanhã. Petrópolis: Vozes, 2014.

SANTACANA, J.; LLONCH, N. Manual de didáctica del objeto en el museo. Gijón: Trea, 2012.

SCHMIDT, M. A.; GARCIA, T. B. Pesquisas em Educação Histórica: algumas experiências. Educar em Revista, número especial, p. 11-31, 2006.

SCHMIDT, M. A.; GARCIA, T. B. O trabalho com objetos e as possibilidades de superação do sequestro da cognição histórica: estudo de caso com crianças nas séries iniciais. In: SCHMIDT, M. A.; GARCIA, T. B. (Org.). Perspectivas de investigação em Educação Histórica, Curitiba: UFPR 2007, v. 1, p. 52-57. 
SEIXAS, P.; CLARK, P. Murals as monuments: students' ideas about depictions of civilization in British Columbia. American Journal of Education, v. 110, n. 2, p. 146-171, 2004.

STRAUSS, A.; CORBIN, J. Basics of qualitative research: techniques and procedures for developing Grounded Theory. Thousand Oaks: Sage, 1998.

Texto recebido em 26 de setembro de 2016. Texto aprovado em 03 de novembro de 2016. 